\title{
Postsynaptic Modulation of Synaptic Efficacy at Mixed Synapses on the Mauthner Cell
}

\author{
Alberto E. Pereda, ${ }^{1}$ Angus C. Nairn, ${ }^{2}$ Laura R. Wolszon, ${ }^{3}$ and Donald S. Faber ${ }^{1}$ \\ 'Department of Anatomy and Neurobiology, Medical College of Pennsylvania, Philadelphia, Pennsylvania 19129, ${ }^{2}$ The \\ Rockefeller University, New York, New York 10021, and 'Department of Biological Sciences, Columbia University, New \\ York, New York 10027
}

Extracellular application of dopamine in the synaptic bed of the lateral dendrite of the goldfish Mauthner $(M-)$ cell enhances both the electrical and chemical components of the mixed excitatory postsynaptic potential (EPSP) evoked by ipsilateral eighth nerve stimulation (Pereda et. al., 1992). We describe here results of experiments designed to determine the locus of action of dopamine and the underlying cellular mechanisms. This amine acts independently on the two modes of transmission, since (1) the percentage increases in the two were not correlated, (2) the time courses of their modifications were independent, and (3) the observed increases in synaptic responses cannot be attributed to a generalized effect on $\mathrm{M}$-cell input conductance, which was increased by dopamine, a change that would rather be expected to shunt the synaptic potentials. Also, dopamine does not produce presynaptic spike broadening and does not modify paired-pulse facilitation, two indications that it acts postsynaptically. The alterations in the mixed EPSP are presumably due to activation of a postsynaptic cAMP-dependent phosphorylation pathway. Specifically, they did not occur if the CAMP-dependent protein kinase inhibitor $\mathrm{PKI}_{5-24}$ was injected intradendritically prior to dopamine application, and they could, on the other hand, be mimicked by injections of the catalytic subunit of the cAMP-dependent protein kinase, PKA $_{\mathrm{CAT}}$. In contrast, neither manipulation altered the $M$-cell input conductance directly or affected the dopamineinduced increase in conductance, suggesting this effect of dopamine is CAMP independent. However, all the dopamine actions were reproduced by intradendritic injections of GTP$\boldsymbol{\gamma}-\mathrm{S}$, and by dopamine $D_{1}$ receptor activation (Pereda et. al., 1992), indicating a divergence of the intracellular regulatory pathways, with the possible involvement of multiple $G$ proteins and second messenger systems. These findings provide strong evidence that dopamine modulates the two components of these mixed excitatory synapses by separate postsynaptic mechanisms, probably involving cAMP-dependent phosphorylations of both glutamate receptors and of the M-cell side of gap junction channels. Thus, electrotonic

Received Sept. 8, 1993; revised Nov. 19, 1993; accepted Nov. 30, 1993

This work was supported in part by National Institute of Health Grant NS15335 to D.S.F. We thank Dr. Edward Koenig for his advice and encouragement.

Correspondence should be addressed to Alberto Pereda, Department of Anatomy and Neurobiology, Medical College of Pennsylvania, 3200 Henry Avenue, Philadelphia, PA 19129.

Copyright (C) 1994 Society for Neuroscience $0270-6474 / 94 / 143704-09 \$ 05.00 / 0$ synapses may well have distinct pre- and postsynaptic regulatory sites.

IKey words: dopamine, postsynaptic, gap junctions, Mauthner cell, glutamate receptors, cAMP]

Neuromodulation, which generally involves the activation of different second messengers systems, is thought to underlie the adaptative characteristics of various neural circuits (Jessel and Kandel, 1993). The efficacy of chemical synaptic transmission in the brain can be modified by activity in modulatory parallel pathways that act on receptors located pre- or postsynaptically (Levitan and Kaczmareck, 1991; Jessel and Kandel, 1993). In the former case, they may influence mechanisms that control neurotransmitter release, while in the latter, they may act on synaptic receptors or by altering the postsynaptic cell's conductance. In contrast to the wealth of data on chemical synapses, there is a limited number of examples of neuromodulation at electrical synapses, which have gap junction plaques as their anatomical substrate (Rennett, 1977). Dopamine is known to decouple retinal horizontal cells in carp and white perch by decreasing gap junctional conductance through a cAMP-dependent mechanism (Teranishi, 1983; Lasater and Dowling, 1985). Since these cells are homologous and the electrical junctions transmit bidirectionally, the coupling presumably plays an important role in synchronizing the electrical activity of the neuronal population, and the biochemical mechanisms underlying this modulation probably occur on both sides of these junctions.

However, electrical synapses are also found between heterologous cells, suggesting that one of the two cellular types but not the other could be the target for synaptic modulation. For example, primary auditory afferents of lower vertebrates are generally connected to their targets by mixed synapses, contacts in which both mcchanisms of transmission coexist (Korn and Faber, 1979), where their main function is the effective transmission of sensory information. In one of the best-studied examples, the eighth nerve excitatory input to the goldfish Mauthner cell (Furshpan, 1964), the auditory afferents terminate on the M-cell lateral dendrite as single, large, myelinated club endings with both chemical synapses and gap junction plaques (Nakajima, 1974; Tuttle el al., 1986). Electrical stimulation of the posterior eighth nerve produces a biphasic excitatory response consisting of a fast electrotonic component, or coupling potential, followed by a chemical glutamatergic EPSP (Furshpan, 1964; Lin and Faber, 1988a; Wolszon and Faber, 1988). We have previously shown there is a dopaminergic innervation of the synaptic bed and that dopamine modulates the excitatory con- 
nection by producing a long-term enhancement of both components of the mixed EPSP, and a cAMP-dependent mechanism has been implicated (Pereda et al., 1992). The mechanisms underlying dopaminergic modulation of the eighth nerve synapses have been explored further, with the aim of determining (1) whether the two modes of transmission are modified independently, (2) the participation of the extrasynaptic membrane conductance, (3) the underlying biochemical mechanisms, and (4) the locus of dopamine's action. The last issue is particularly relcvant for clectrotonic coupling since the gap junctions are formed by the apposition of two hemichannels (one from each cell), raising the question of whether both have to be modified in order to increase coupling. Our results support the idea that dopamine modulates this synaptic input through a postsynaptic mechanism involving cAMP-dependent phosphorylations of both glutamate receptors and gap junction channels.

\section{Materials and Methods}

Adult goldfish (Carassius auratus) were used for the experiments; the surgical and anesthetic procedures were similar to those described previously (Faber and Korn, 1978).

Electrophysiological recordings. Intracellular current-clamp recordings were obtained in vivo from the lateral dendrite about $250-300 \mu \mathrm{m}$ from the M-cell soma. Electrodes were filled with either $2.5 \mathrm{M} \mathrm{KCl}(8-$ $20 \mathrm{M} \Omega$ ) or $5 \mathrm{M} \mathrm{K}$-acetate (3-6 M $\Omega$ ), unless they were also used for intracellular pressure injection. The composite monosynaptic EPSPs were obtained by low-strength stimulation of the posterior branch of the eighth nerve (Fig. $1 A$ ). Stimulation intensity was such that the range of response amplitudes was $6.9-40.3 \mathrm{mV}$ for the coupling potential (Fig. $1 B, \mathrm{e}$ ) and 1.9-9.4 $\mathrm{mV}$ for the chemical EPSP (Fig. $1 B$, c). Even the largest electrotonic PSPs were subthreshold for orthodromic spike initiation at the axon's initial segment, presumably due to attenuation along the dendrite (Faber and Korn, 1978). The M-axon was activated antidromically by an electrode placed on the spinal cord (Fig. 1 $A$, AD), and the magnitude of the antidromic action potential was taken as an indicator of the $\mathrm{M}$-cell input resistance, given that the soma-dendritic membrane of this neuron does not support spike electrogenesis (Faber and Korn, 1978). All measurements were made after averaging sets of 12 or more traces. The amplitudes of the coupling potential and chemical EPSP were measured from the baseline to their peaks, although highfrequency eighth nerve stimulation indicates there is a residual coupling potential at the time of the EPSP peak (Fig. 1B). While this procedure may result in an overestimation of chemical EPSP amplitude, difference waveforms calculated before and after modifications show that measured changes in amplitude are reliable (Fig. $1 C, \mathrm{~d}, \mathrm{~d}^{\prime}$ ). Also, due to this temporal overlap, peak amplitudes were considered to be more reliable than other measures, such as the total area attributed to each response. Since the $\mathbf{M}$-cell has a very fast membrane time constant $(390$ $\mu \mathrm{sec}$; Faber and Korn, 1978) coupling potential duration was used as an inference of presynaptic spike duration. Half-decay time was used instead of half-width in order to avoid possible contamination of the measurement due to the stimulation artifact on the raising phase of the coupling potential. Student's $t$ test was used to assess statistical significance of the obtained data.

Dopamine application. A second pipette situated $40-100 \mu \mathrm{m}$ above the M-cell s lateral dendrite and about the same distance from the soma as the intracellular electrode (Fig. $1 A$ ) was used for local pressure ejections $(5-15 \mathrm{psi}, 1-45 \mathrm{sec})$ of dopamine $(10 \mathrm{~mm}$, dissolved in $130 \mathrm{~mm}$ $\mathrm{NaCl}$ and $10 \mathrm{~mm}$ HEPES, $\mathrm{pH}$ 7.2). Given the distance between the electrode and the M-cell, volume dilution, and difficulties inherent with extracellular pressure ejection, we estimate that the effective dopamine concentration was at least 2 orders of magnitude less in this in vivo preparation.

Intracellular injections. The catalytic subunit of the cAMP-dependent protein kinase $(0.3-0.5 \mathrm{mg} / \mathrm{ml})$ was purified from bovine heart as described (Kaczmareck et al., 1981). The kinase was dialyzed against 10 mM HEPES ( $\mathrm{pH} 7.5$ ), $150 \mathrm{~mm} \mathrm{KCl}$ and diluted into $10 \mathrm{~mm}$ HEPES, $0.5 \mathrm{M} \mathrm{KCl}$. The peptide inhibitor of cAMP-dependent protein kinase (Walsh, $\mathrm{PKI}_{5-24}$-amide, $300-900 \mu \mathrm{M}$; Sigma) and the nonhydrolyzable analog of guanosine-tri-phosphate GTP- $\gamma-\mathrm{S}$ (300-600 $\mu \mathrm{M}$; Sigma) were dissolved in $10 \mathrm{~mm}$ HEPES ( $\mathrm{pH} 7.2$ ), $0.5 \mathrm{M} \mathrm{KCl}$, and pressure injected

\begin{tabular}{|c|c|c|c|}
\hline Experiment & el (\%con) & $\operatorname{ch}(\% \operatorname{con})$ & ad $(\% c o n)$ \\
\hline dopa 3 & 7.6 & 26.4 & -11.7 \\
\hline dopa 5 & 32.9 & 30.3 & -9.1 \\
\hline dopa 9 & 26.5 & 13.1 & -6.4 \\
\hline dopa 10 & 24.8 & 85.7 & -1.16 \\
\hline dopa 16 & 11.6 & 6.8 & -2.5 \\
\hline dopa 17 & 20.2 & 46.9 & -6.25 \\
\hline dopa 18 & -4.7 & 19.9 & -3.36 \\
\hline dopa 19 & 44.2 & 58.3 & -2.9 \\
\hline dopa 20 & 37 & 59.6 & -8.9 \\
\hline dopa 26 & 35.5 & 61.9 & -6.69 \\
\hline dopa 27 & 32 & 43 & 0.5 \\
\hline dopa 32 & 23.4 & 53.7 & -16.6 \\
\hline dopa 33 & 40.8 & 52.3 & 13.5 \\
\hline dopa 35 & 32.6 & 32.8 & -15.8 \\
\hline dopa 43 & 72.6 & 52.1 & -18.5 \\
\hline dopa 44 & 35.7 & 45.3 & -3.9 \\
\hline dopa 45 & 16.1 & 40.5 & -15 \\
\hline dopa 46 & 26.6 & 24.8 & 0.19 \\
\hline dopa 47 & 31.9 & 26.9 & -12.3 \\
\hline dcl 5 & 28.3 & 57.9 & 1 \\
\hline Average & 28.8 & 41.9 & -7.8 \\
\hline $\operatorname{SEM}( \pm)$ & 3.5 & 4.3 & 1.4 \\
\hline
\end{tabular}

Data are percentage changes produced by dopamine in electrotonic coupling (el), chemical EPSP (ch), and the antidromic spike height (ad) in 20 experiments.

intracellularly through the recording electrode (Fig. $1 A$ ). The transient appearance of a depolarizing recurrent IPSP, due to an increase in intracellular $\mathrm{Cl}^{-}$, was used as an indication of a successful pressure injection.

\section{Results}

\section{Dopamine enhances synaptic transmission} and increases input conductance

Figure $1 B$ illustrates the mixed synaptic transmission at these contacts (as in Furshpan, 1964). Low-frequency $(0.5 \mathrm{~Hz})$ eighth nerve stimulation evoked a biphasic excitatory response consisting of a fast electrotonic component (labeled "e"; Furshpan, 1964), followed by a chemical glutamatergic EPSP (labeled "c"; Wolszon and Faber, 1988). At a higher frequency of stimulation $(100 \mathrm{~Hz})$ the chemical component fatigued, while the electrical component remained (the slight decrease observed is probably due to partial refractoriness of presynaptic axons). The computer-calculated difference of the two traces ( $\triangle$ PSP) shows the net chemical synaptic component.

Pressure ejection of dopamine outside the lateral dendrite produces a long-term enhancement of both components of the mixed EPSP (as in Pereda et al., 1992). This effect is best seen by subtracting the control waveform from that recorded after dopamine injection ( $\Delta$ PSP in Fig. 1C). In the previous study, the potentiations averaged $28.8 \pm 3.5 \%( \pm$ SEM) for the electrical and $41.9 \pm 4.3 \%( \pm$ SEM $)$ for the chemical EPSP $(n=20$; Pereda et al., 1992; see Table 1), these changes being significantly different from control $(p<0.01)$. The enhancements began within 3-8 $\mathrm{min}$, and lasted throughout the recording period in all experiments, the longest duration being 90 min after the application.

The experiment illustrated in Figure $2 A_{I}-A_{3}$ demonstrates that 
Figure 1. $A$, Diagram of the experimental arrangement. $A D$, antidromic stimulation; 8th. $N$., eighth nerve stimulus. $V 1$, intradendritic voltage recording electrode, also used for intracellular pressure $(P r$.$) injections of the protein-$ kinase inhibitor $\mathrm{PKI}_{5-24}(P K I)$, catalytic subunit of the cAMP-dependent protein-kinase $(P K A)$ or GIP- $\gamma$-S; $V 2$, second electrode placed extracellularly for pressure application $(P r$.) of dopamine $(D A)$. Inset represents a single eighth nerve afferent ending (Club Ending), in which both mechanisms of synaptic transmission, electrical and chemical, coexist. $B$, Mixed excitatory postsynaptic potential evoked by posterior eighth nerve stimulation. Two superimposed traces of averaged responses obtained by stimulating at the same strength but at different frequencies $(0.5$ and $100 \mathrm{~Hz}$, respectively). The response to $0.5 \mathrm{~Hz}$ stimulation consists of both the electrotonic coupling potential $(e)$ and a chemical excitatory postsynaptic potential (EPSP; $c$ ), whereas at $100 \mathrm{~Hz}$, there is only a coupling potential, decreased slightly in amplitude owing to partial refractoriness of the afferents. The inset $(\triangle P S P)$ is the computer-calculated difference of the two traces, showing that the net chemical EPSP starts after the peak of the coupling potential. $C$, Dopamine enhances synaptic excitation of the M-cell lateral dendrite. Superimposed averages $(n=12)$ obtained in the control (control) and 10 min after dopamine injection $(D A)$. Inset $(\triangle P S P)$ is the computer-calculated difference between the two waveforms, demonstrating that both components increased. All measurements were made after averaging sets of 12 or more traces. The amplitude of the chemical EPSP was measured from baseline to peak. Since high-frequency eighth nerve stimulation indicates there is a residual coupling potential during the peak of the chemical PSP (see $B$ ), this may result in an overestimate of the chemical EPSP amplitude. However, difference waveforms calculated before and after modifications show that measured changes in amplitude are reliable $\left(d, d^{\prime}\right)$.

\section{A}
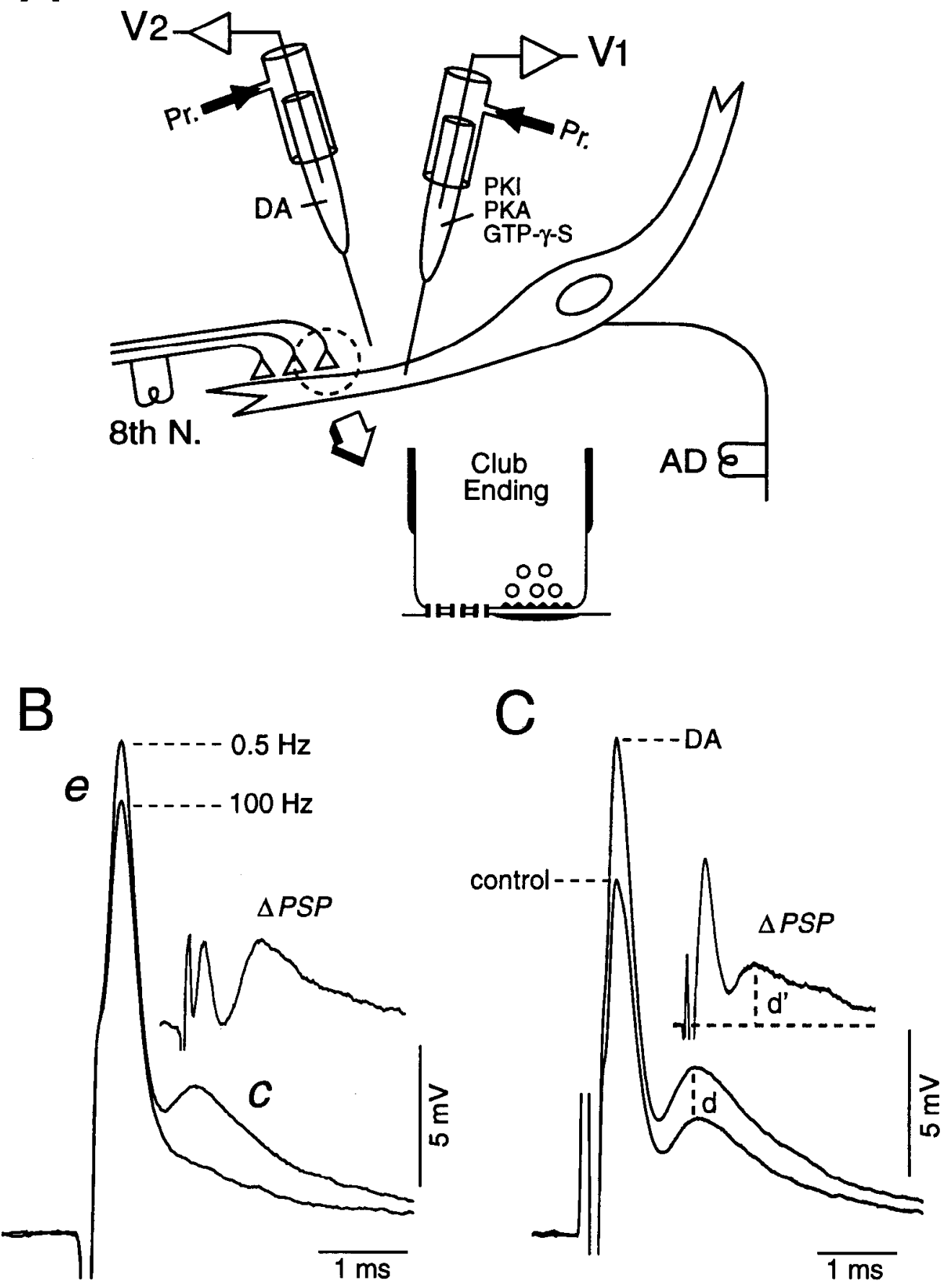

the effects of dopamine are due to separate actions on both electrotonic and chemical synapses, and not to a reduction in the M-cell's input conductance. First, as in most cases, dopamine did not increase the two components by the same percentage (Fig. $21_{1}$ ), and it often had a greater effect on the chemical EPSP (13 of 20 experiments; see Table 1), although in some other experiments the increase in the coupling potential was more prominent ( 5 of 20 cases; see Table 1 ). In fact, the effects on the two components were significantly different $(p<0.01)$. Second, dopamine actually increased input conductance, as indicated by a significantly decreased $(p<0.01)$ antidromic spike height (Fig. $2 A_{2} ; 16$ of 20 cases; see Table 1), which averaged $-7.8 \pm-1.4 \%( \pm$ SEM, $n=20$; Pereda et al., 1992). In the illustrated experiment, the two potentiations had similar time courses, while the increased input conductance developed more gradually (Fig. $2 A_{3}$ ). In other experiments, the dopamine-induced changes in the two synaptic potentials could be dissociated in time. This finding is illustrated in Figure $2 B$, where after the first two of three dopamine applications only the chemical EPSP was enhanced, while the coupling potential and spike height only began to exhibit their typical modifications after a third application. 

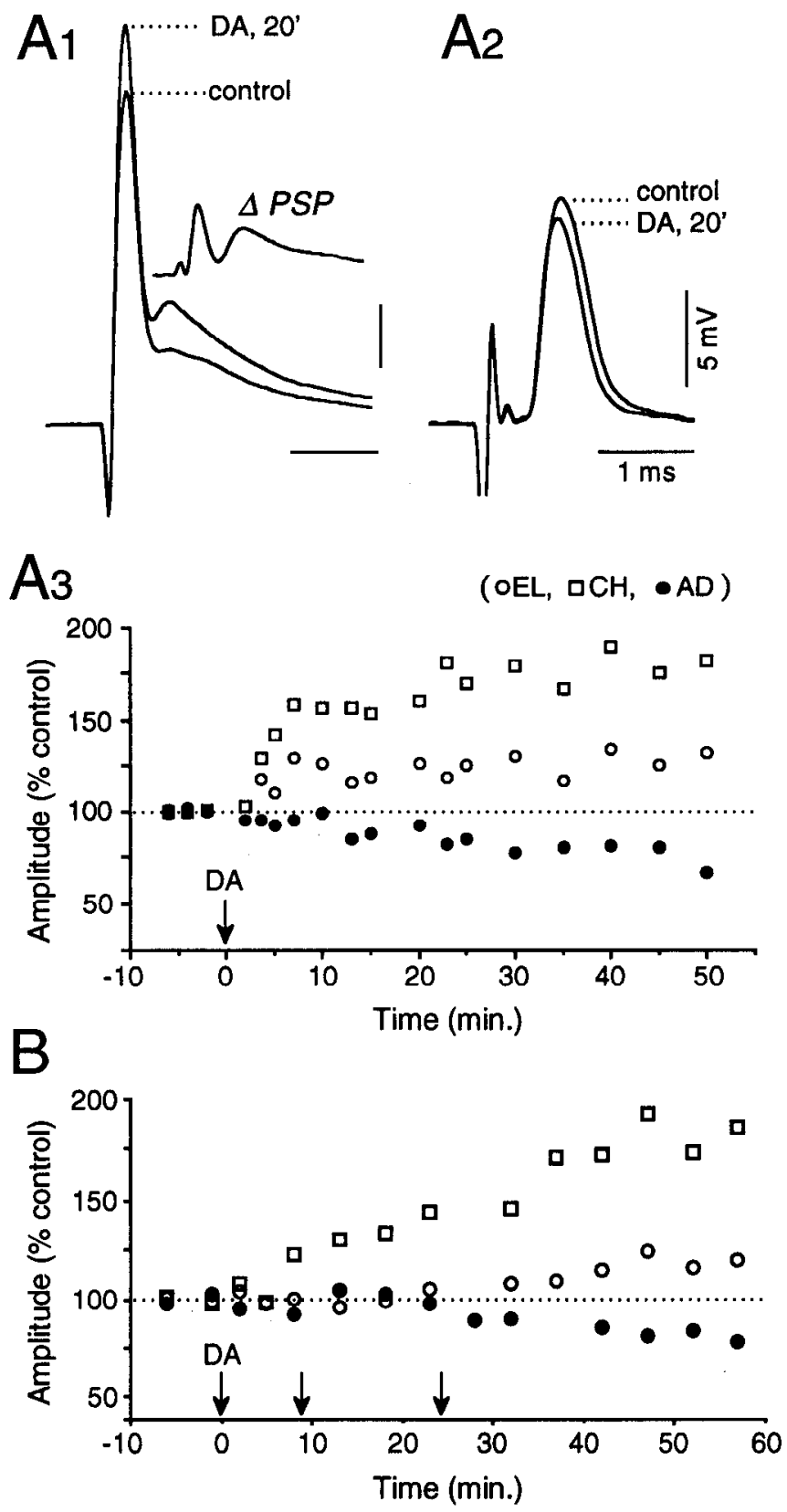

Figure 2. Independent dopamine effects on synaptic transmission and dendritic input conductance. $A_{l}$, Dopamine enhanced both components of the mixed excitatory response (as in Pereda et al., 1992), but not by the same percentage. Superimposed averages $(n=20)$ obtained in the control and $20 \mathrm{~min}$ after $\left(D A, 20^{\prime}\right)$ dopamine application. Inset $(\triangle P S P)$ is the computer-calculated difference between the two waveforms. $A_{2}$, In the same experiment, antidromic spike height, a measure of M-cell input resistance, was reduced, as shown by superimposed averages ( $n$ $=20$ ) obtained in the control and $20 \mathrm{~min}$ after dopamine application $\left(D A, 20^{\prime}\right) . A_{3}$, Time courses of dopamine effects in the experiment of $A_{1}$ and $A_{2}$, plotting changes in the amplitude of coupling potential $(O$ $E L)$, chemical EPSP $(\square C H)$, and antidromic spike $(-A D)$. All magnitudes are expressed as the percentages of their control values. A single dopamine application ( $D A$, arrow) at time 0 produced a long-term enhancement of both synaptic components and a sustained reduction in antidromic spike height. $B$, In a different experiment, the dopamineinduced changes were temporally dissociated. Three applications ( $D A$, arrows) were used, and modifications of the coupling potential and the antidromic spike height were only apparent after the third application.
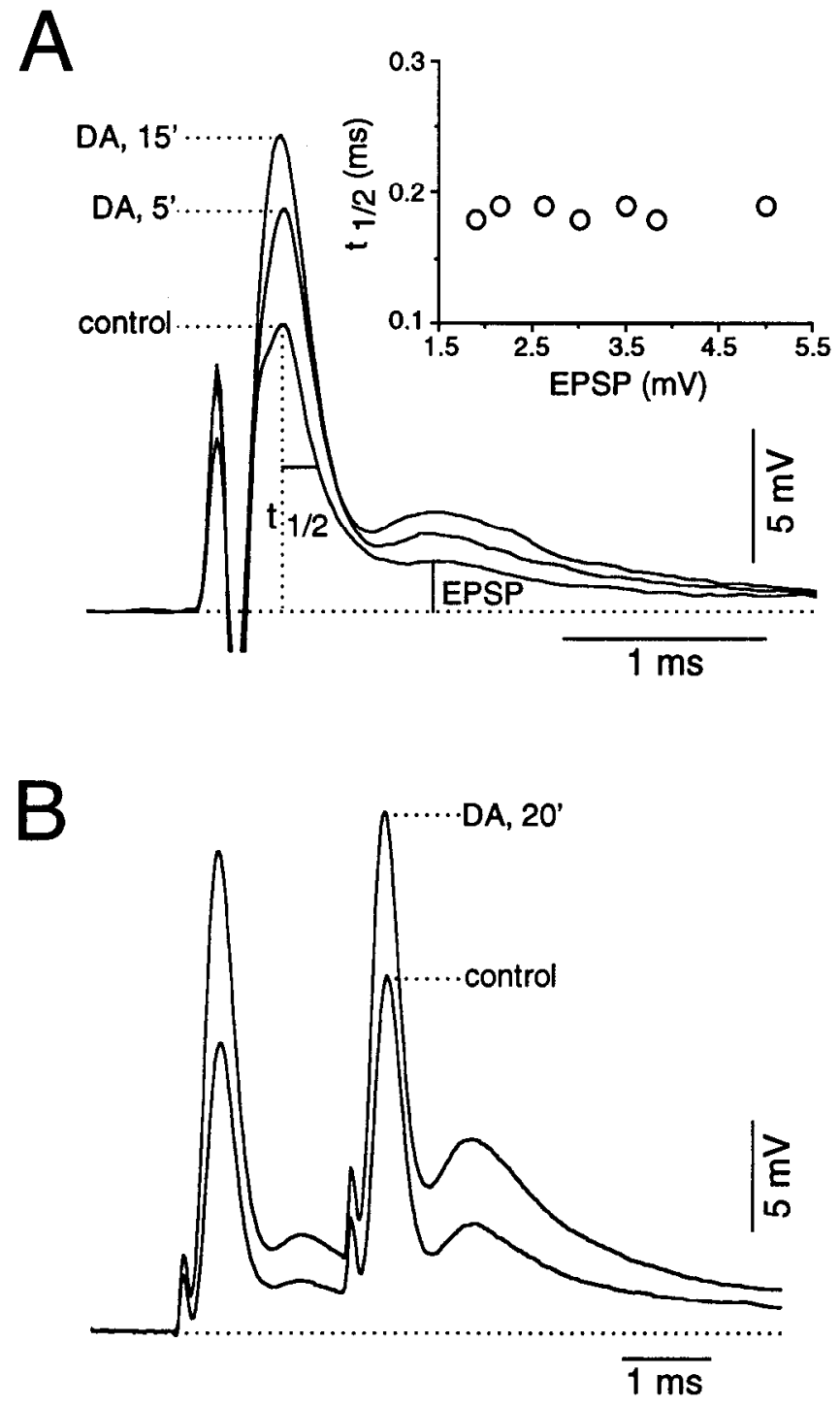

Figure 3. Evidence that dopamine does not modify chemical synaptic transmission by acting presynaptically. $A$, Coupling potential half-decay time $\left(t_{1 / 2}\right)$ was not altered by dopamine. Superimposed averages $(n=$ 20 ) obtained in the control and 5 and 15 min after applying dopamine $(D A)$ are shown. Note that a weak stimulus strength was used, such that the control chemical EPSP was less than two millivolts. Inset, Plot of $t_{1 / 2}$ versus chemical EPSP amplitude obtained at different times after dopamine application, showing constancy of the kinetic parameter. $B$, Superimposed averages $(n=20)$ of synaptic responses to paired-pulse stimulation were obtained before and $20 \mathrm{~min}$ after dopamine application $(D A)$.

\section{Site of action of dopamine}

To localize and identify the mechanisms responsible for the above-described effects, we first looked for evidence of presynaptic involvement in the facilitation of the chemical EPSP. Specifically, we examined the possibility that dopamine may have enhanced transmitter release via spike broadening (Klein and Kandel, 1978), previously shown to modify the input-output relationship at these chemical synapses (Lin and Faber, 1988b). However, presynaptic spike duration, as inferred from the halfdecay time ( $t_{1 / 2}$; see Materials and Methods) of the electrotonic EPSP, was virtually unchanged by dopamine, averaging $96.9 \pm$ $2.5 \%( \pm \mathrm{SEM})$ of the control value $(n=17)$. An example is shown in Figure $3 A$, where a low stimulation strength that evoked 


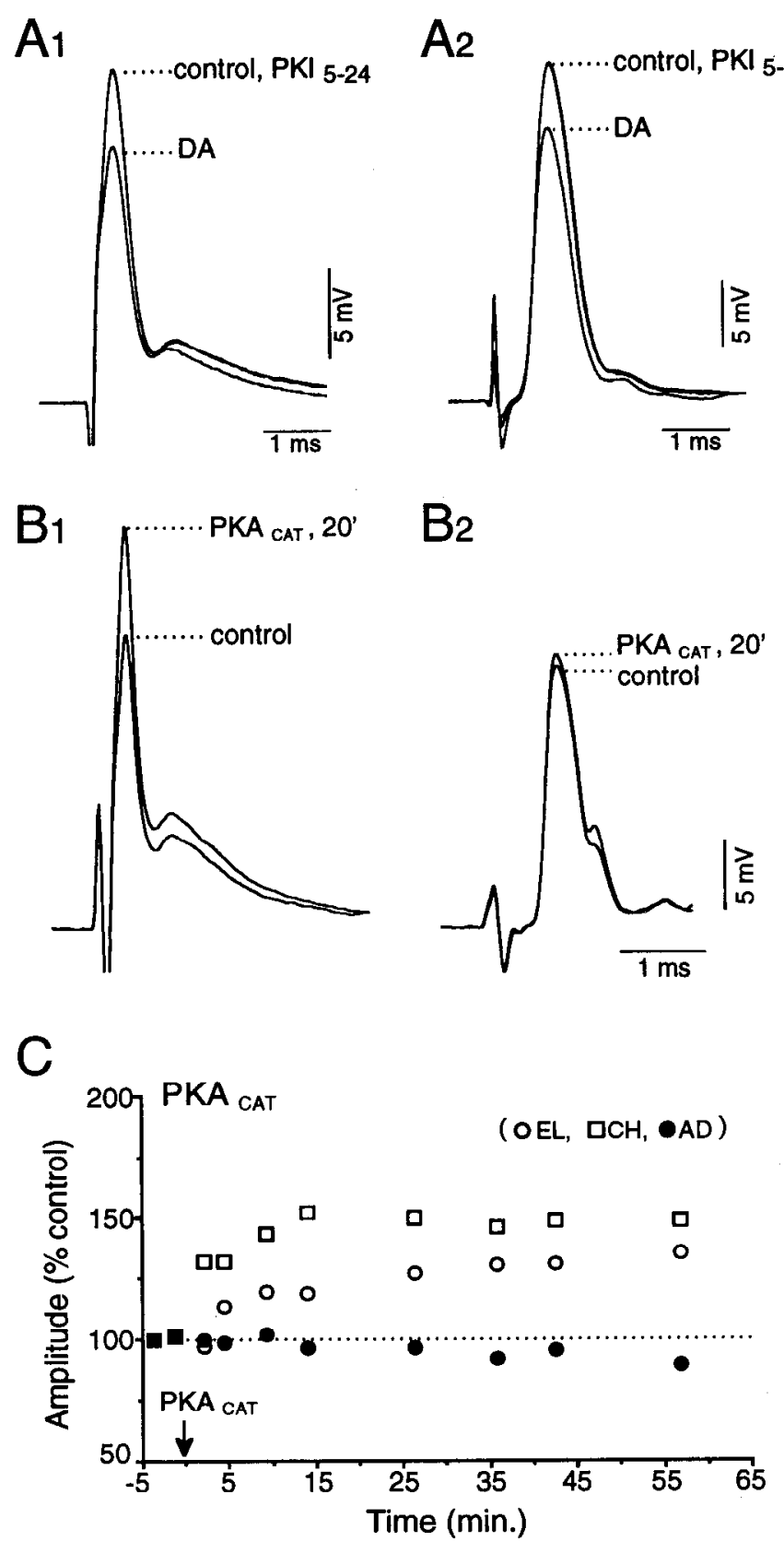

Figure 4. $A_{1}$ and $A_{2}, \mathrm{PKI}_{5-24}$ blocks the dopamine-induced enhancements of the mixed excitatory synaptic responses. Three superimposed averages of synaptic responses obtained in the control, $10 \mathrm{~min}$ after intradendritic $\mathrm{PKI}_{5-24}$ injection, and then $10 \mathrm{~min}(D A)$ after extracellular dopamine application. $\mathbf{P K I}_{5-24}$ at this concentration did not have a direct effect, but dopamine now produced decreases in both components of the EPSP and in the antidromic spike height, presumably by decreasing input resistance. $B_{1}$ and $B_{2}$, Intradendritic injections of PKA enhance both components of the mixed synaptic response. $B_{t}$, Superposition of averaged synaptic responses $(n=12)$ obtained before (control) and 20 min after PKA injection (PKA $\mathrm{PAT}_{\mathrm{CA}}$ ). Both the coupling potential and chemical EPSP were enhanced. $B_{2}$, Antidromic spikes recorded at the same times as in $B_{l}$. Note that the spike height, a measure of the cell's input resistance, changed only slightly. $C$, Time course of the effects of

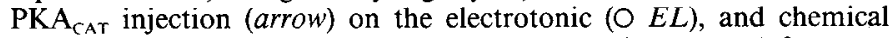
$(\square C H)$ components and on antidromic spike height $(A D)$ from another experiment. All are expressed as percentages of their control values and each point is an average of 12 consecutive traces. a small chemical EPSP was used to examine the correlation between the coupling potential's $t_{1 / 2}$ and the amplitude of the chemical component before and after dopamine application. As expected, dopamine enhanced both EPSP components in this experiment. However, as seen in the inset, $t_{1 / 2}$ remained constant after dopamine application, even though the chemical EPSP grew progressively.

We next examined whether dopamine affects paired-pulse facilitation of the EPSP, since previous work concluded this potentiation has a presynaptic origin (Lin and Faber, 1988b; see Wolzson, 1989, for suggestion of a secondary postsynaptic involvement with paired population EPSPs). Also, a reduction in the facilitation of the second EPSP is usually taken as an indirect evidence of presynaptic involvement in other examples of synaptic plasticity (McNaughton, 1982; Zalutsky and Nicoll, 1991). For this purpose, synaptic responses to paired pulses were obtaincd in control and after dopamine application (Fig. 3B). Paired-pulse facilitation was estimated using the expression

$$
\% \text { Facilitation }=\left[\left(\text { Response }_{2}-\text { Response }_{1}\right) /\left(\text { Response }_{1}\right)\right] 100 \% \text {. }
$$

In four experiments where the first chemical EPSP was enhanced by $37.5 \%$, the paired-pulse facilitation after dopamine application averaged $109 \%$ of that obtained in the control. These results further support the notion that the increase in chemical transmission produced by dopamine is not due to presynaptic modulation.

\section{Involvement of second messengers}

Given that the indirect evidence suggested a postsynaptic locus for the enhancement of the chemical EPSP, we took advantage of the accessibility of the M-cell's lateral dendrite for injection of agents known to affect second messenger systems. Dopamine normally acts through mechanisms that involve the activation of the cAMP pathway (Lacey, 1989), and our previous data showed that intradendritic injections of cAMP produce increases in both components of the excitatory response (Wolszon and Faber, 1989). Nevertheless, since cAMP is a small molecule that can pass through the gap junctions, these observed effects could be mediated either pre- or postsynaptically. In order to determine the involvement of the cAMP system in dopamine's actions, $\mathrm{PKI}_{5-24}$, a highly specific inhibitor of the catalytic subunit of the cAMP-dependent protein kinase, was injected intradendritically prior to the extracellular application of the amine. The injection of the peptide alone generally did not have any effect. In eight experiments with $\mathrm{PKI}_{5-24}$, the electrotonic potential, chemical EPSP, and spike height averaged $104.6 \pm 3.23 \%$ $( \pm$ SEM $), 103.3 \pm 2.0 \%( \pm$ SEM $)$, and $102.2 \pm 2.5 \%( \pm$ SEM $)$ of their control values, respectively, following the injection of $\mathrm{PKI}_{5-24}$. However, the peptide did prevent the dopamine-induced enhancement of both components of the excitatory response $(n=7)$. In fact, after pretreatment with $\mathrm{PKI}_{5-24}$, dopamine actually produced decreases in the electrotonic coupling $(-10.4 \pm 3.6 \%, \pm$ SEM $)$, the chemical EPSP $(-9.8 \pm 5.09 \%$, \pm SEM), and the antidromic spike height $(-9.3 \pm 3.67 \%, \pm$ SEM), all these actions presumably being due to a decreased input resistance of the dendrite (Fig. $4 A_{1}, A_{2}$ ).

In addition to implicating a cAMP-dependent phosphorylation pathway, these findings with $\mathrm{PKI}_{5-24}$ further support the deduction that dopamine acts postsynaptically. Since the molecular weight of $\mathrm{PKI}_{5-24}$ (2222.4) is about twice the size of the largest compound known to cross gap junctions (Saéz et al., 1993), its effect most likely was restricted to the injection site. 

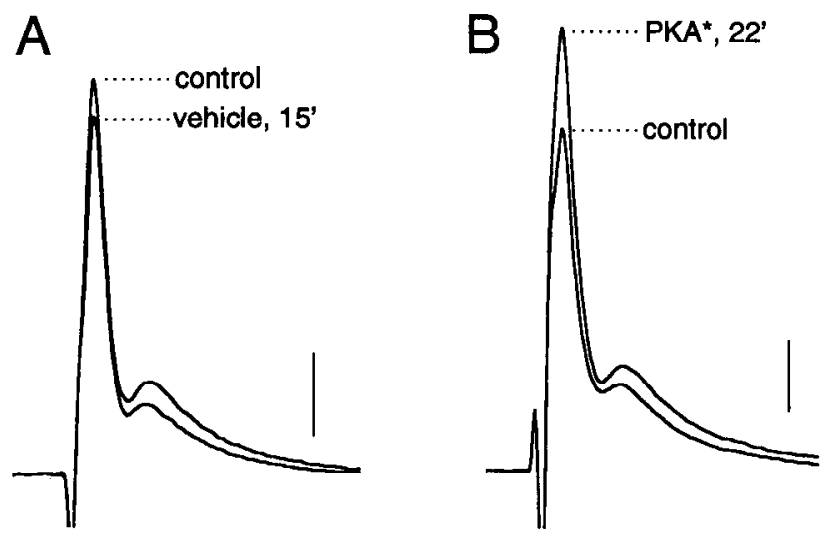

To verify this conclusion, we next examined the effects of intracellular injection of the catalytic subunit of the cAMP-dependent protein kinase ( $\mathrm{PKA}_{\mathrm{CAT}}$ ), which has a molecular weight of 40,000 Da. PKA ${ }_{\text {CAT }}$ mimicked the synaptic effects of dopamine in that it produced sustained significant increases $(n=7$, $p<0.01)$ in both components of the mixed excitatory response: $21.9 \pm 3.9 \%( \pm$ SEM , range 9.4-29.4) for the coupling potential and $20.8 \pm 5.2 \%( \pm$ SEM, range $10.6-39.3)$ for the chemical component (Fig. $4 B_{i} ; n=7$ ). Interestingly, injection of the enzyme was also able to reproduce the time course of the changes that followed the dopamine injection, as is illustrated in Figure $4 C$. Resting potential remained unchanged during the experiments, and in agreement with the $\mathrm{PKI}_{524}$ experiments, PKA did not significantly $(p>0.01)$ decrease antidromic spike height (Fig. $4 B_{2}$ ), which averaged $97.95 \pm 2.4 \%( \pm$ SEM) of its control value after injection $(n=7)$.

One important control for these $\mathrm{PKI}_{5-24}$ and $\mathrm{PKA}_{\mathrm{CAT}}$ results is the injection of the vehicle alone, which as shown in Figure $5 A$, produced small decreases, rather than enhancements, in both components of the EPSP (Fig. $5 A$ ). This finding suggests that increases induced by $\mathrm{PKA}_{\mathrm{CAT}}$ may be underestimated. Overall the electrotonic coupling potential, the chemical EPSP and the AD spike height averaged $86.9 \%, 94.1 \%$, and $99.7 \%$ of their original values, respectively, after vehicle injection $(n=$ 3). Given that the catalytic subunit of PKA is heat labile, we tried to inactivate it by first heating it at $60^{\circ} \mathrm{C}$ for $10 \mathrm{~min}$. Injection of the resulting solution still produced an increase in both components of the mixed EPSP (Fig. $6 B$ ), by about $25-$ $30 \%(n=2)$, and it did not affect the antidromic spike (not shown). However, when PKA solution was boiled, injection of this control solution produced effects similar to those obtained

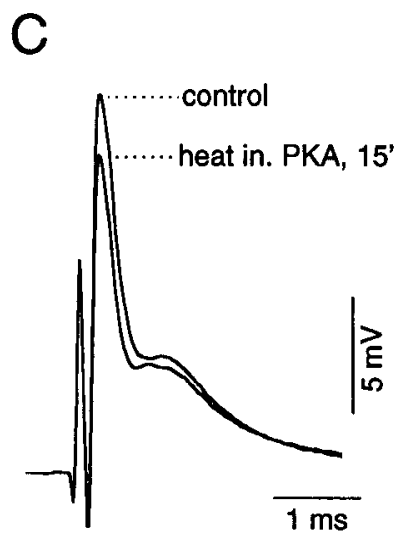

Figure 5. Injections of vehicle and heat-inactivated PKA do not enhance the eighth nerve-cvoked responses. In $A-C$, averaged responses obtained before and at the indicated times after injections of vehicle alone $(A)$ or with PKA either heated to $60^{\circ} \mathrm{C}\left(B, P K A^{*}\right)$ or inactivated by boiling $(C)$ are superimposed. Note that the injections of vehicle and of heat-inactivated PKA reduced the size of the synaptic responses, while the enzyme retained its activity when heated to only $60^{\circ} \mathrm{C}$.

with the vehicle (Fig. $5 C$ ). Specifically, the coupling potential, chemical EPSP, and AD spike height averaged $86.2 \%, 98 \%$, and $108.3 \%$ of their original values, respectively, after heat-inactivated $\mathrm{PKA}_{\text {CAT }}$ injection $(n=3)$.

The cAMP-dependent and -independent effects of dopamine on synaptic and nonsynaptic membranes might be due to the activation of two different subtypes of receptors. However, the dopamine $\mathrm{D}_{1}$ receptor antagonist $\mathrm{SCH}-23390$ has been shown to block all of these effects (Pereda et al., 1992). All known actions of liganded $D_{1}$ receptors involve activation of a $G$ protcin (Fclder ct al., 1989; Laccy, 1989; Siblcy, 1990), regardless of whether the latter controls enzyme activity or an ionic channel. Therefore, the injection of GTP $-\gamma-\mathrm{S}$, a nonhydrolyzable analog of GTP that irreversibly activates $G$ proteins, should produce both the cAMP-dependent and -independent effects of dopamine. We found that GTP- $\gamma$-S injections produced not only a significant $(p<0.05)$ increase in both components (Fig. $6 A, B_{l}$ ) of the excitatory response (averaging $20.9 \pm 3.6 \%, \pm \mathrm{SEM}$, for the coupling, and $24.7 \pm 5.8 \%$, \pm SEM, for the EPSP, $n=5$ ), but also a significant $(p<0.05)$, albeit slight, reduction in AD spike height $(-5.6 \pm 1.3, \pm \mathrm{SEM}$, range -1.3 to $-9,6 \%, n=$ 5 ), comparable to that produced by dopamine application (Fig. $6 B_{2}$ ). In three other cases, the effects of GTP- $\gamma-S$ on synaptic transmission could not be quantified because all responses, including the antidromic spike, exhibited markedly increased amplitude fluctuations following the injection.

\section{Discussion}

The results from the present study (see also Pereda et al., 1992) are consistent with the idea that dopamine modulates the eighth nerve excitatory synaptic input by acting independently on both
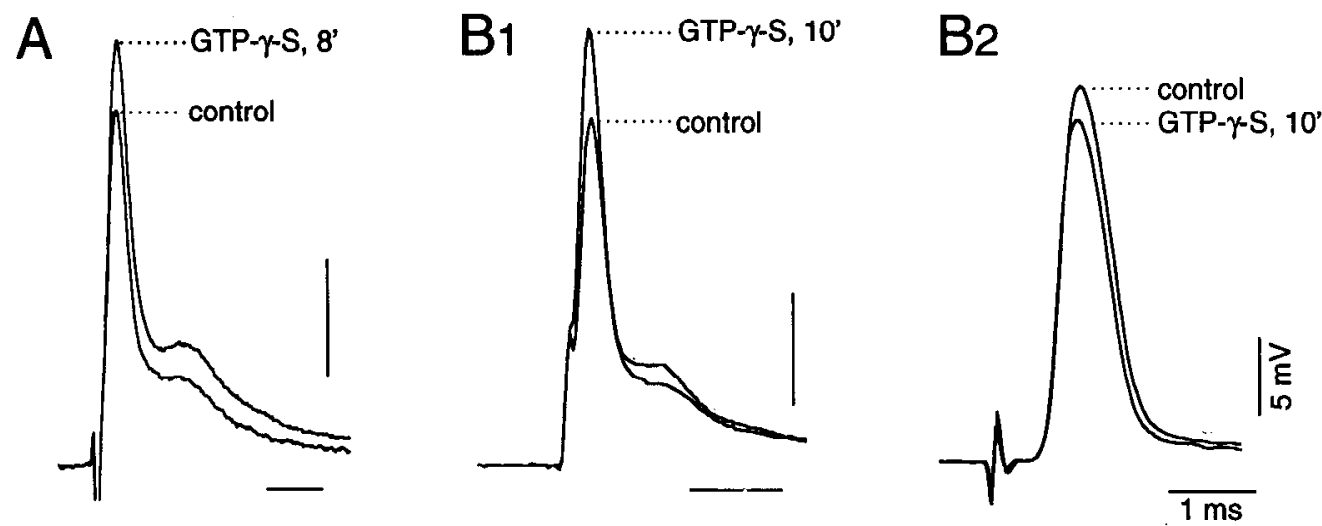

Figure 6. Intradendritic injections of GTP- $\gamma-S$ produced all the effects of dopamine applications. $A$, Superposition of averaged EPSPs before (control) and $8 \mathrm{~min}$ after GTP- $\gamma-\mathrm{S}$ injection. $B$, and $B_{2}$, Averaged responses from another experiment, illustrating that GTP- $\gamma$-S not only enhanced the eighth nerveevoked responses $\left(B_{i}\right)$ but also decreased antidromic spike height $\left(B_{2}\right), 10$ min after GTP- $\gamma$-S injection. 


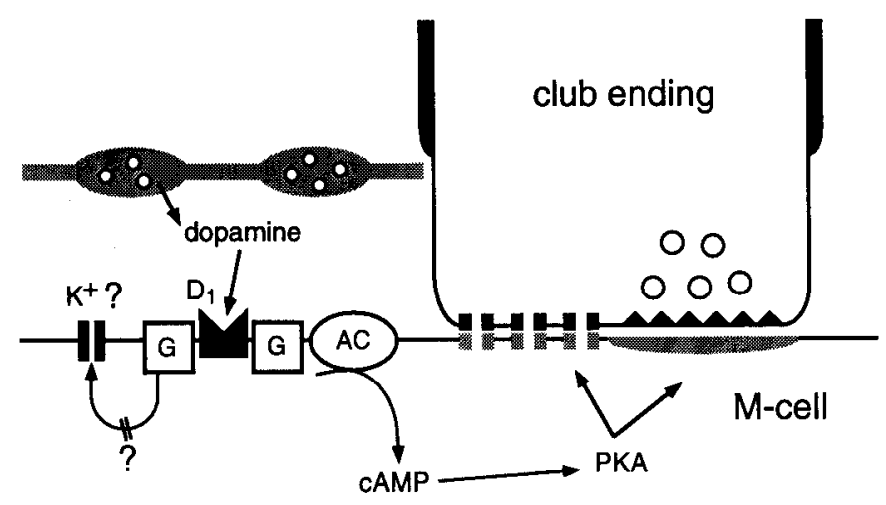

Figure 7. Schematic representation of dopaminergic innervation of the synaptic bed of the M-cell and the postsynaptic cascade activated by dopamine. The modulator, released from nearby varicosities, diffuses to $M$-cell s lateral dendrite, where it interacts with a $D_{1}$ receptor. Consequent activation of a $G$ protein triggers two sets of reactions: (1) activation of the cAMP pathway, presumably leading to phosphorylation of glutamate receptors (shaded region opposed to the presynaptic active zone) and of gap junction hemichannels, and (2) modulation of $\mathrm{K}^{+}$channels, which may involve a different second messenger pathway (?) or a direct activation of the $G$ protein on the channel. The cAMP might also cross the gap junctions to modulate presynaptic functions (not shown). $A C$, adenylate cyclase; $P K A$, cAMP-dependent protein kinase.

electrical and chemical transmission, since there could be differential effects on the two modes of transmission. Moreover, the observed increases are the opposite of those that could occur if due only to the decreased input conductance of the M-cell, that follows application of the amine (Pereda et al., 1992). Finally, the observed effects on both components of the synaptic response and membrane conductance could be dissociated in time.

These results are presumably functionally significant, given that there is a dopaminergic innervation of the synaptic bed of the M-cell lateral dendrite characterized by thin fibers containing small dopamine-positive varicosities. These varicosities are in close proximity to the afferent fibers, but apparently do not contact pre- or postsynaptic elements (Pereda et al., 1992). The advantage of studying the cellular basis of the synaptic modulation exerted by dopamine in this in vivo preparation is that both electrophysiological recordings and intracellular injections of molecules can be performed at the region where the synaptic contacts and the dopaminergic fibers are located (Nakajima, 1974; Pereda et al., 1992). In the present study, our results support the idea that dopamine acts postsynaptically on the EPSPs via a cAMP-dependent phosphorylation pathway. First, its effect could be prevented by prior injection of $\mathrm{PKI}_{5-24}$, a specific inhibitor of $\mathrm{PKA}_{\mathrm{CAT}}$. Second, intradendritic injection of PKA $_{\text {CAT }}$ produced an enhancement of both components of the mixed EPSP that was comparable in magnitude and in time course to that produced by the extracellular application of dopamine. Since PKA $_{\text {CAT }}$ is a high-molecular-weight molecule $(40,000 \mathrm{Da})$, it cannot cross gap junctions and its direct effects are thus restricted to the site of injection. While we cannot exclude, the contribution of a retrograde messenger, such as arachidonic acid or nitric oxide (Schumann and Madison, 1991; Williams et al., 1993), to the observed effects of dopamine, we can conclude that they require activation of the postsynaptic cAMP pathway.

Since the observed effects occur quite rapidly after dopamine or $\mathrm{PKA}_{\mathrm{CAT}}$ application, modifications of existing gap junctions and glutamate receptors are most likely involved. Indeed, cAMP affects junctional conductance in most tissues and cell lines that have been studied to date (Saéz et al., 1993). Connexins, the family of proteins that form these channels, are considered to be good substrates for phosphorylation, the best-known examples being connexin 32 and 43 (Saéz et al., 1986, 1993; Moreno et al., 1993). The effects reported here are consistent with those of cAMP found in many non-neuronal tissues (Bennett et al., 1991; Saéz et al., 1993). However, these results are the opposite of those obtained in another neuronal system, the retina, where dopamine decreases junctional conductance and reduces electrotonic and dye coupling between horizontal cells (Piccolino et al., 1982; Lasater and Dowling, 1985) by elevating cAMP levels. This apparent discrepancy is best explained by the idea that the effect of a given intracellular regulatory system may vary due to differences in the involved conncxins (morc than 16 have been described to date) or in the cell types expressing the same connexin (Bennett et al., 1991). In the case of the M-cell, preliminary evidence, including antibody blockade of electrotonic coupling (Yox et al., 1990) and immunocytochemistry (unpublished observations), suggests that the connexin at these junctions is homologous to mammalian connexin 43.

Neurotransmitter receptors are particularly appropriate targets for the modulation of synaptic transmission, since they are central to the process of signal transduction across the plasma membrane. The most likely mechanism underlying the dopamine-mediated enhancement of the chemical EPSP is the phosphorylation of a non-NMDA glutamate receptor similar to that proposed for the dopamine-induced enhancement of glutamate currents at horizontal cells (Knapp and Dowling, 1987; Liman et al., 1989; Knapp ct al., 1990), which is also cAMP dependent. Modulation of glutamate responses by cAMP-dependent phosphorylation was also suggested from studies of hippocampal neurons (Greengard et al., 1991; Wang et al., 1991). Evidence for direct phosphorylation of a kainate (GluR6) glutamate receptor was reported recently, and a specific phosphorylation site for PKA was identified by site-directed mutagenesis (Raymmond et al., 1993; Wang et al., 1993).

Neuromodulatory transmitters that act through a second messenger pathway can affect many substrate proteins within the postsynaptic cell, and thereby elicit a coordinated cellular response (Levitan and Kaczmareck, 1990). Our studies indicate that dopamine enhances the synaptic efficacy of the excitatory input from the eighth nerve by promoting a coordinated response that involves at least three different targets: both components of the mixed synaptic response and the extrasynaptic dendritic membranc. A possible functional significance of this modulation could be a lowered behavioral threshold of the fish for the acoustically evoked escape response. However, the fact that there is a decrease in the M-cell's lateral dendrite's input conductance might appear to be in contradiction with the enhancement of the eighth nerve synaptic responses, suggesting that the latter effect was probably underestimated. One idea is that a change in dendritic input conductance would nonspecifically reduce the overall efficacy of other synaptic connections and could consequently provide a mechanism for selecting the modified synapses, as they would be the only ones to have their efficacy raised. Consistent with this idea, preliminary results showed that extracellular application of dopamine at the M-cell soma did not produce any decrease in antidromic spike height 
(A. E. Pereda, D, S. Faber, and H. Korn, unpublished observation), suggesting that the dopamine-evoked conductance increase is a property restricted to the dendritic membrane.

A cAMP-dependent phosphorylation mechanism is not implicated in the effect of dopamine on dendritic input conductance, as it is not blocked by $\mathrm{PKI}_{5-24}$ and is not reproduced by $\mathrm{PKA}_{\mathrm{CAT}}$. Yet, all dopamine actions are apparently mediated by the same receptor subtype since the dopamine $D_{1}$ receptor antagonist SCH-23390 blocks them equally (Pereda et al., 1992). Evidence that GTP- $\gamma-\mathrm{S}$ injected postsynaptically reproduced both cAMP-dependent and -independent effects suggests there may be two populations of dendrite $D_{1}$ receptors linked to different $G$ proteins and second messenger systems, as was shown to be the case for the dopamine actions on rat anterior pituitary cells. There, the dopamine $\mathrm{D}_{2}$ receptor modulates both potassium and calcium currents, by acting through two different $G$ proteins (Lledo et al., 1992). Interestingly, it has been reported that $D_{1}$ receptors can induce an increase in $\mathrm{IP}_{3}$ turnover by activating the enzyme phospholipase A (Felder et al., 1989; Mahan et al., 1990). The targets of this modulatory action most likely are $\mathrm{K}^{+}$channels, since they are subject to dopamine regulation in many tissues (Lacey, 1989). Indeed, an increased membrane conductance without a detectable change in the resting potential of the $\mathrm{M}$-cell implicates an increased $\mathrm{K}^{+}$conductance (Faber and Korn, 1978).

Finally, these results are consistent with all actions of dopamine having a postsynaptic origin (Fig. 7) and, in the case of the synaptic potentials, they implicate phosphorylation of both glutamate receptors and gap junctional proteins. Given that gap junctional channels are formed by the apposition of two hemichannels, one from each cell, the results obtained by the intradendritic injection of $\mathrm{PKI}_{5-24}$ and $\mathrm{PKA}_{\mathrm{CAT}}$ suggest that an increased junctional conductance can be obtained by modifying the channels at the dendritic side (M-cell) of the junctional plaques alone. Modulation of hemichannels by cyclic nucleotides and dopamine has been reported in isolated catfish horizontal cells (De Vries and Schwartz, 1992). This modulation may be asymmetric, which would imply that both sides of the gap junctional plaque can be modified independently, consistent with the fact that heterologous gap junctions could also be formed between heterologous cell types expressing different connexins (Saéz et al., 1993), which may be subject to different regulatory controls. As with chemical synapses, this characteristic may confer electrical synapses with distinct presynaptic and postsynaptic modulatory sites.

\section{References}

Bennett MVL (1977) Electrical transmission: a functional analysis and comparison with chemical transmission. In: Handbook of physiology, Vol I, The nervous system, Sect I, Cellular biology of neurons (Kandel ER, ed), pp 357-416. Baltimore: Williams and Wilkins.

Bennett MVL, Barrio LC, Bargiello TA, Spray DC, Hertzberg E, Saéz JC (1991) Gap junctions: new tools, new answers, new questions. Neuron 6:305-320.

De Vries SII, Schwartz ER (1992) Hemi-gap-junction channcls in solitary horizontal cells. J Physiol (Lond) 445:201-230.

Faber DS, Korn H (1978) Electrophysiology of the Mauthner cell: basic properties, synaptic mechanisms, and associated networks. In: Neurobiology of the Mauthner cell (Faber DS, Korn H, eds), pp 47132. New York: Raven.

Felder CC, Jose PA, Axelrod J (1989) The dopamine-1 agonist, SKF 82526, stimulates phospholipase-C activity independent of adenylate cyclase. J Pharmacol Exp Ther 248:171-175.

Furshpan EJ (1964) Electrical transmission at an excitatory synapse in a vertebrate brain. Science 144:878-880.
Greengard P, Jen J, Nairn AC, Stcvens CF (1991) Enhancement of the glutamate response by cAMP-dependent protein kinase in hippocampal neurons. Science 253:1135-1138.

Jessel TM, Kandel E (1993) Synaptic transmission: a bidirectional and self-modifiable form of cell-cell communication. Cell $72 /$ Neuron 10[Suppl]:1-30.

Kaczmareck LK, Jennings KR, Stromwasser F, Nairn AC, Walter U, Wilson FD, Greengard P (1980) Microinjection of the catalytic subunit of cyclic AMP-dependent protein kinase enhances calcium action potentials of bag cell neurons in cell culture. Proc Natl Acad Sci USA 77:7487-7491.

Klein M, Kandel ER (1978) Presynaptic modulation of voltage dependent $\mathrm{Ca}^{++}$current: mechanism for behavioral sensitization in Aplysia californica. Proc Natl Acad Sci USA 75:3512.

Knapp AG, Dowling JE (1987) Dopamine cnhances excitatory amino acid-gated conductances in cultured retinal horizontal cells. Nature $325: 437-439$.

Knapp AG, Schmidt KF, Dowling JE (1990) Dopamine modulates the kinetics of ion channels gated by excitatory amino acids in retinal horizontal cells. Proc Natl Acad Sci USA 87:767-771.

Korn H, Faber DS (1979) Electrical interactions between vertebrate neurons: fields effects and electrotonic coupling. In: The neurosciences 4th study program (Schmitt FO, Worden FG, eds), pp 333-358. Cambridge, MA: MIT Press.

Lacey MG (1989) Towards understanding dopamine. Semin Neurosci $1: 137-143$.

Lasater E Dowling JE (1985) Dopamine decreases conductance of the electrical junctions between cultured retinal horizontal cells. Proc Natl Acad Sci USA 82:4299-3029.

Levitan I, Kaczmareck L (1991) The neuron, cell and molecular biology. New York: Oxford UP

Liman ER, Knapp AG, Dowling J (1989) Enhancement of kainate gated currents in retinal horizontal cells by cyclic AMP-dependent protein kinase. Brain Res 481:399-402.

Lin JW, Faber DS (1988a) Synaptic transmission mediated by single club endings on the goldfish Mauthner cell. I. Characteristics of electrotonic and chemical postsynaptic potentials. J Neurosci 8:13021312.

Lin JW, Faber DS (1988b) Synaptic transmission mediated by single club endings on the goldfish Mauthner cell. II Plasticity of excitatory postsynaptic potentials. J Neurosci 8:1313-1325.

Lledo PM, Homburger. V, Bockaert J, Vincent JD (1992) Differential $\mathrm{G}$ protein-mediated coupling of $\mathrm{D}_{2}$ dopaminc rcceptors to $\mathrm{K}^{+}$and $\mathrm{Ca}^{2+}$ currents in rat anterior pituitary cells. Neuron 8:455-463.

Mahan LC, Burch RM, Monsma FJ, Sibley DR (1990) Expression of striatal $D_{1}$ dopamine receptors coupled to inositol phosphate production and $\mathrm{Ca}^{2+}$ mobilization in Xenopus oocytes. Proc Natl Acad Sci USA 87:2196-2200.

McNaughton BL (1982) Long-term enhancement and short-term potentiation in rat fascia dentata act through different mechanisms. J Physiol (Lond) 324:249-262.

Moreno AP, Fishman GI, Eghbali B, Spray DC (1993) Unmasking electrophysiological properties of connexins 32 and 43: transfection of communication-deficient cells with wild type and mutant connexins. In: Progress in cell research, Vol 3, Gap junctions (Hall JE, Zampighi, GA, Davis, RM, eds), pp 127-132. Amsterdam: Elsevier.

Nakajima Y (1974) Finc structure of the synaptic cndings on the Mauthner cell of the goldfish. J Comp Neurol 156:375-402.

Pereda A, Triller A, Korn H, Faber DS (1992) Dopamine enhances both electrotonic coupling and chemical excitatory postsynaptic potentials at mixed synapses. Proc Natl Acad Sci USA 89:12088-12092.

Piccolino M, Neyton J, Gerschenfeld H (1982) Decrease of gap junction permeability induced by dopamine and cyclic adenosine $3^{\prime}: 5^{\prime}$ monophosphate in horizontal cells of turtle retina. J Neurosci 4:24772488 .

Raymmond LA, Blackstone CD, Huganir RL (1993) Phosphorylation and modulation of recombinant GluR6 glutamate receptors by cAMP dependent protein kinase. Nature 361:637-641.

Saéz JC, Spray DC, Nairn AC, Hertzberg EL, Greengard P, Bennett MVL (1986) cAMP increases junctional conductance and stimulates phosphorylation of the 27-kDa principal gap junction polypeptide. Proc Natl Acad Sci USA 83:2473-2477.

Saéz JC, Berthoud VM, Moreno AP, Spray DC (1993) Gap junctions. Multiplicity of controls in differentiated and undifferentiated cells and possible functional implications. In: Advances in second messenger 
and phosphoprotein research, Vol 27 (Shirish Shenolikar S, Nairn, AC, eds), pp 163-198. New York: Raven.

Schumann EM, Madison DV (1991) A requirement for the intracellular messenger nitric oxide in long-term potentiation. Science 254: 1503-1506.

Sibley D, Monsma FJ Jr (1992) Molecular biology of dopamine receptors. Trends Pharmacol Sci 13:61-69.

Teranishi T, Negishi K, Kato S (1983) Dopamine modulates S-potential amplitude and dye-coupling between external horizontal cells in carp retina. Nature 301:243-246.

Tuttle R, Masuko S, Nakajima Y (1986) Freeze fracture study of the large myelinated club ending synapse on the goldfish Mauthner cell: special reference to the quantitative analysis of gap junctions. J Comp Neurol 246:202-211.

Wang LY, Salter MW, MacDonald JF (1991) Regulation of kainate receptors by cAMP-dependent protein kinase and phosphatases. Science 253:1132-1135.

Wang LY, Taverna F, Huang XP, Mc Donald JF, Hampson DR (1993) Phosphorylation and modulation of kainate receptor (GluR6) by cAMP-dependent protein kinase. Nature 361:637-641.
Williams JH, Errington ML, Li Y-G, Lynch MA, Bliss TVP (1993) The search for retrograde messengers in long term potentiation. Semin Neurosci 5:149-158.

Wolszon L (1989) Modulation of the synaptic efficacy in the goldfish Mauthner cell. PhD Thesis, State University of New York at Buffalo.

Wolszon L, Faber DS (1988) Fast EPSPs evoked in the Mauthner cell by sensory afferents are due to NMDA receptor activation. Soc Neurosci Abstr 14:939.

Wolszon L, Faber DS (1989) The effects of postsynaptic levels of cyclic AMP on excitatory and inhibitory responses of an identified central neuron. J Neurosci 9:784-797.

Yox DP, Faber DS, Nicholson BJ (1990) Gap-junction antibody attenuates electrical coupling between the goldfish Mauthner (M-) cell and its eighth nerve afferents. Soc Neurosci Abstr 16:185.

Zalutsky RA, Nicoll RA (1990) Comparison of two forms of longterm potentiation in single hippocampal neurons. Science 248:119248. 